\title{
Arbor
}

\section{Pedro Teixeira y su viaje por Mesopotamia}

\section{José Javier Fuente del Pilar}

Arbor CLXXX, 711-712 (Marzo-Abril 2005), 627-643 pp.

Pedro Teixeira es un integrante notable de la ilustre nómina de los viajeros portugueses que, a finales del s. XVI y principios del XVII, ensancharon para Occidente las fronteras del mundo. Su conocimiento en España se debe a la publicación en 1994 de su obra "Relaciones del Origen, Descendencia y Sucesión de los Reyes de Persia, y de Harmuz, y de un viaje hecho por el autor dende la India hasta Italia por tierram, en edición realizada por el profesor Eduardo Barajas Sala, lamentablemente fallecido en 1997.

En este artículo se ofrece una reseña biográfica de Pedro Teixeira, y un análisis del viaje narrado por el autor en la última parte de sus "Relaciones": el que desde Ormuz le conducirá, a través de Mesopotamia, hasta la costa del Mediterráneo.

En 1984, dos pequeñas editoriales madrileñas embarcadas en una colección común, dedicada a rescatar libros de viajeros hispánicos olvidados o ya inencontrables, coeditaron una obra escrita en castellano por un enigmático viajero portugués del siglo XVI: un texto casi desconocido y nunca editado antes en España ${ }^{1}$ que llevaba por título Relaciones de Pedro Teixeira del origen, descendencia y svccesion de los Reyes de Persia, y de Harmuz, y de un viaje hecho por el mismo autor dende la India Oriental hasta Italia por tierra ${ }^{2}$. El libro contenía la relación completa de un viaje realizado casi íntegramente a pie desde la India hasta Italia: un do- 
cumento apasionante, cargado de datos históricos, geográficos y etnográficos tomados de primera mano por un viajero escritor que, además, para sorpresa de los editores exhibe en su narración una riqueza léxica de extraordinario interés literario.

La historia de esta primera edición en España de las Relaciones de Pedro Teixeira se remonta a 1989, cuando el profesor Eduardo Barajas Sala, a la sazón catedrático de Filología Hispánica de la Universidad de Extremadura, me hizo llegar, junto a un amplio comentario sobre el viajero portugués, una separata editada en Portugal sobre los portuguesismos incluidos en el texto castellano de su crónica ${ }^{3}$. Aquella publicación y la figura del portugués que escribía en castellano, presentada con la impecabilidad intelectual del profesor Barajas, llamó enseguida nuestra atención y, bajo su tutela, tras algunos años de cartas, pruebas y correcciones, dimos finalmente a imprenta su edición de las Relaciones, para la que escribió un extenso prólogo.

El profesor Barajas, tristemente desaparecido en 1997, se constituyó durante aquellos años en el inductor de mi interés por la literatura de viajes portuguesa de los siglos XVI-XVII, y debo reconocer que cuanto sé (me atrevería a decir "se sabe» en nuestro país) sobre Pedro Teixeira proviene de sus trabajos. Nada nuevo diré, pues, en estos apuntes que no haya dicho él antes, por ejemplo, en la edición española de las Relaciones de Pedro Teixeira que, con Eduardo Barajas como guía, tuve el honor de coordinar.

\section{Antecedentes literarios: Crónicas portuguesas de viajes a Oriente en los siglos XVI y XVII}

Entre las numerosas crónicas viajeras sobre el próximo o el lejano Oriente de los siglos XVI y XVII, siempre ocuparán un lugar destacado las de los viajeros portugueses. Sus textos contribuyeron como pocos a abrir la insondable puerta de esa parte del mundo a los ojos cultos de Europa. Algunos experimentaron incluso un envidiable éxito comercial: por reseñar el mejor ejemplo, las peripecias lejanas de un extraordinario viaje por China y Japón, recogidas en las Peregrinaciones de Fernao Mendes Pinto, obra impresa originalmente en Lisboa en 1614, conoció una traducción al castellano sólo seis años después ${ }^{4}$ y enseguida ediciones francesas, inglesas, alemanas... Algo similar sucedió con Antonio de Andrade, jesuita, nacido hacia 1580 en Oleiros, quien viajó a la India y al Tibet en 1600 , y sus Cartas del Descubrimiento del Gran Catayo $(1624)^{5}$, vieron una inmediata traducción al castellano (Madrid, 1626), al francés (París, 1626), dos al italiano (una en Roma y otra en Nápoles, ambas en 1627), al polaco (1628) y al flamenco (Gante, 1631). 
Pedro Teixeira y su viaje por Mesopotamia

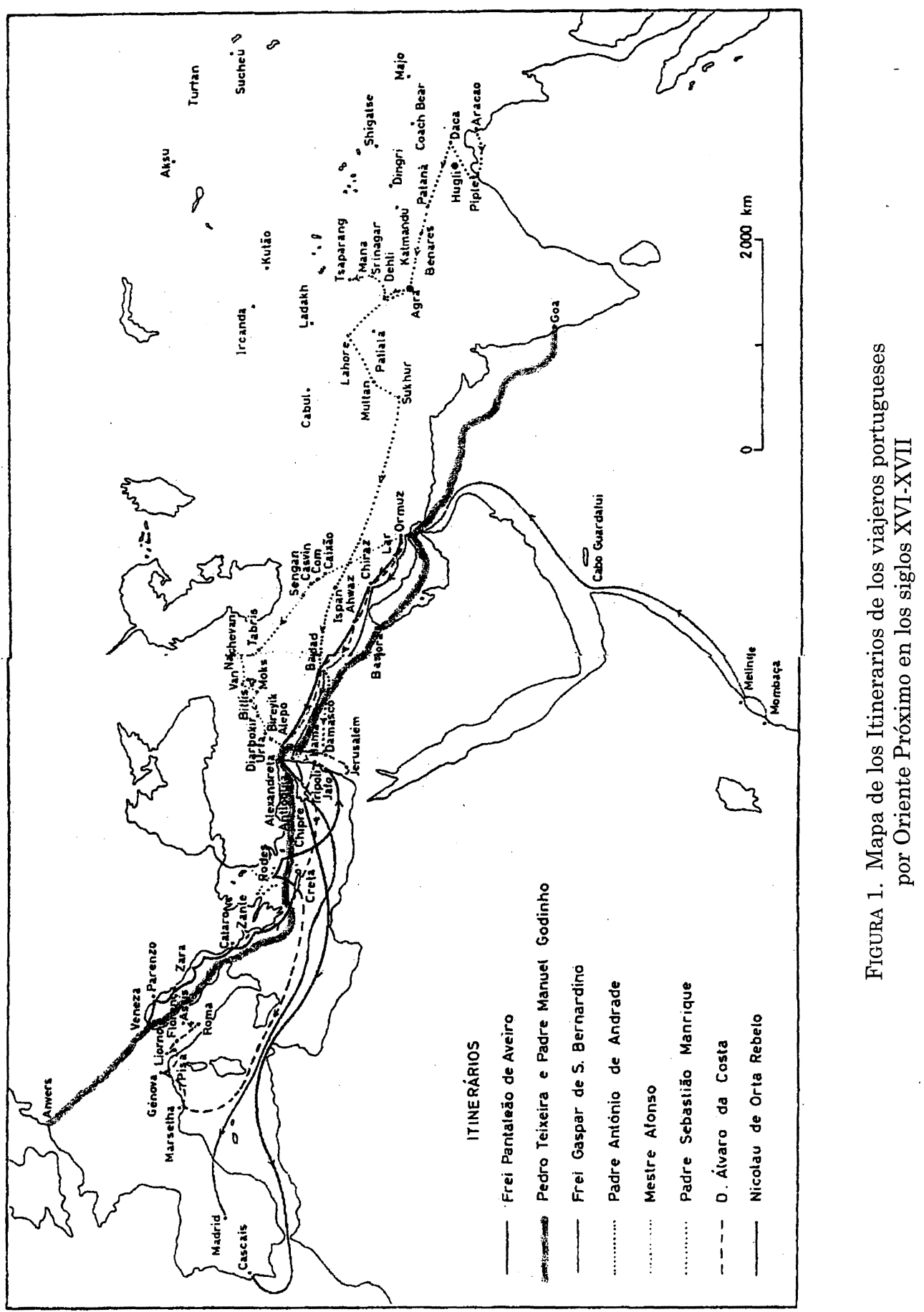


En lo que se refiere a Oriente Próximo, la literatura portuguesa de viajes de los siglos XVI y XVII presenta igualmente obras de indudable importancia, aunque su difusión no alcanzara ni de lejos los ejemplos mencionados. Por seguir un cierto orden cronológico ${ }^{6}$, es imprescindible comenzar con la mención al libro que recoge el viaje del franciscano Frei Pantaleao de Aveiro, nacido en esta localidad en 1520, quien viajó a Tierra Santa en 1561 y permaneció en Jerusalén año y medio: su título completo es Itinerário da terra Sancta e suas particularidades, composto por Frey Pantaliam Daveiro, y fue publicado en Lisboa en 1593.

En 1565, el médico Mestre Afonsos realiza un viaje desde la ciudad portuaria india de Cochin, en el actual estado de Kerbala, hasta Lisboa que narra en su Itinerário da ilha de Ormuz até Tripoli na Barberia e d'ahi até Rochela de França; un texto que permaneció inédito hasta el siglo XIX.

En 1601, Frei Gaspar de S. Bernardino, franciscano y natural de Lisboa, parte para la India y regresa a Portugal cuatro años después, describiendo su viaje en su Itinerário da India por terra até este Reino de Portugal com A Descripçam De Hierusalem / Dirigido A Raynha de Espanha Margarida De Austria Nossa Senhora.

En el buque que trae de vuelta a Frei Gaspar, embarca también Nicolau Orta Rebelo quien, tras una estancia en África, realiza la misma ruta que Frei Gaspar y pone por escrito sus experiencias en su Relaçao da Jornada que fez da India para o Reino, texto que concluyó en 1607 pero que permaneció inédito hasta $1972^{7}$.

D. Alvaro da Costa, natural de Lisboa, fue un militar cuya carrera transcurrió en la India y que con el grado de capitán mayor tomó parte en la guerra que en 1608 sostuvieron los musulmanes en Persia contra los portugueses. Cuando regresó a Portugal en 1611 escribió un Tratado de viagem que fez D. Álvaro da Costa da India Oriental a Europa nos anos de 1610 e 1611, por via da Pérsia e Turquia, con particular relaçao da Terra Santa e Cidade de Jerusalém..., que se conserva manuscrito e inédito en la Biblioteca Pública de Évora ${ }^{8}$.

El P. Sebastiao Manrique, natural de Oporto, ingresó en 1604 en el convento de San Agustín de Goa. Los avatares acontecidos durante sus viajes por Oriente se imprimieron en Roma en 1633 con el título de Itinerário de las missiones del India Oriental.

Por último, el P. Manuel Godinho, jesuita, natural de Montalvao, vivió varios años en Oriente y regresó a Portugal siguiendo casi el mismo itinerario que Pedro Teixeira, el viajero sobre el que centraremos 


\section{Pedro Teixeira y su viaje por Mesopotamia}

enseguida nuestra atención, reflejando sus vivencias en su Relaçao do novo camiinho que fez por terra, e mar vindo da India para Portugal no anno 1663.

En el contexto de estos viajes se enmarca el realizado por Pedro Teixeira: los itinerarios de los viajeros que los protagonizaron, en cuyas crónicas se describe con mayor o menor profundidad las diferentes regiones del Oriente Próximo, quedan reflejados en el mapa adjunto.

Todos los relatos mencionados están escritos por los propios protagonistas, quienes, al tiempo que narran sus viajes, aventuras y desventuras, ofrecen curiosas noticias de la realidad que se presenta ante sus ojos: el paisaje, la flora, la fauna, la caza y la pesca, los productos naturales y manufacturados, las viviendas y los modos de vida de sus moradores, etc. Casi todos procuran reflejar sus impresiones de manera fiel y objetiva: cuentan lo que vieron con sus propios ojos, pero también lo que oyeron a personas de confianza. Estas características generales dotan a estos textos de una personalidad común, de un cierto estilo compartido, cuyo rasgo más destacable es la amenidad narrativa puesta al servicio del interés por ofrecer, de manera casi periodística, la mayor información posible.

\section{Reseña Biográfica de Pedro Teixeira}

Del autor de las Relaciones se conoce muy poco, apenas lo que él mismo nos cuenta en su libro. Sin duda, los dos estudios más extensos sobre la vida de Pedro Texeira son los ofrecidos por Eduardo Barajas y Donald Ferguson ${ }^{9}$, aunque ambos autores se limitan a realizar un ensayo de interpretación biográfica basado fundamentalmente en la propia obra del viajero portugués y en otras fuentes historiográficas del último cuarto del siglo XVI y posteriores.

Según el alemán Meyer Kayserling ${ }^{10}$, Pedro Teixeira nació probablemente en alguna localidad del norte de Portugal situada entre los ríos Duero y Miño, en el seno de una familia de judíos portugueses que terminaría asentándose en Lisboa. Se ignora el lugar y la fecha exacta de su nacimiento, incluso si fue educado en la fe de sus padres, pues nada dice al respecto en su obra, si bien en ella se nos presenta como un buen creyente "temeroso de Dios", por lo que podría deducirse que terminó abrazando el catolicismo.

De la lectura de sus Relaciones parece desprenderse que Teixeira se dedicaba al comercio (aunque es probable que antes se ganara la vida como sol- 
dado) y que tal fue el motivo que le indujo a enrolarse en un barco de una de las dos flotas que partieron de Portugal hacia Goa en 1586. Nada dice en su texto de esta ciudad, donde residió varios años y debió conocer muy bien. Sólo nos informa de que entre 1590 y 1591 se instala en la ciudad india de Cochin, en 1596 en Harmuz y un año después en la ciudad septentrional persa de Mazandaron, hasta que regresó nuevamente a Goa para embarcarse hacia Malaca en 1597, donde permaneció dos años y medio, al cabo de los cuales viajó a Manila como escala a Nueva España. Así llega a Acapulco el 1 de diciembre de 1600 para dirigirse luego a caballo a la ciudad de México donde entró el día de Navidad. En la ciudad azteca permaneció hasta el 2 de mayo de 1601, y a finales de ese mismo mes se hizo a la mar desde Veracruz con destino a España. El buque en el que viajaba estuvo a punto de naufragar frente a Cuba, pero logró atracar en el puerto de La Habana, para reanudar el viaje el 15 de julio. Pasó por Florida, las islas Bermudas y los bancos de bacalao de Terranova. Tras sortear los ataques de los corsarios ante las costas del Algarve llegó a Sevilla y, finalmente, a Lisboa el 8 de octubre de $1601^{11}$.

Después de este accidentado viaje, Pedro Teixeira, en contra de su voluntad, se vio obligado a volver a la India ("la cosa que menos me entrara en el pensamiento", escribe) para resolver un asunto de deudas económicas impagadas. Así, volvió a embarcarse el 28 de marzo de 1603 en una de las flotas que zarparon con rumbo a la India bajo el mando de Pero Furtado de Mendoza, arribando a Goa el 14 de octubre. Debió solucionar con presteza sus cuitas financieras (nada dice al respecto, aun cuando sí nos había informado de la existencia del problema), pues cuatro meses después emprendía el regreso a Portugal, aunque en esta ocasión, hastiado de tanto viaje marítimo, decidió relizar el camino de vuelta por tierra. La narración de este viaje conforma el corazón más narrativo e intenso, por su amenidad e interés aventurero, de sus Relaciones, y a él nos referiremos en extenso más adelante, aunque ahora avancemos un resumen breve.

En febrero de 1604, Texeira abandonó Goa en un navío que le conduciría al Golfo Pérsico, alcanzando Ormuz un mes más tarde. Tras un intento frustrado, logró llegar a Basora en agosto de 1603. Resuelto a regresar a Europa por tierra, se unió a una caravana que atravesaría hacia el norte el desierto de Arabia. Aquella travesía comenzó el 2 de septiembre, y le llevaría a recorrer Mesopotamia, a la sazón bajo dominio otomano, pasando por ciudades que describe espléndidamente en su crónica: Mashad Ali, Kerbala, Bagdad; y al otro lado del Éufrates, Ana y Alepo, donde Teixeira permanecerá casi dos meses. El 5 de abril, reemprendió su viaje y llegó a Alejandreta el 8 de abril de 1605, para zarpar rumbo a Venecia, con escalas en Chipre y en Zante, ciudad a la que arribó el día 11. 


\section{RELACIONES}

DE

PEDRO TEIXEIRA

\section{D'EL ORIGEN}

DES CE N D E N C I A

Y S G C ESSION

de los Reyes de Purfia, y de Harmuz,

Y DE VN VIAGE HECHO

POR EL MISMO.AYTOR

dende la India Oriental hafta Italia por tierra.

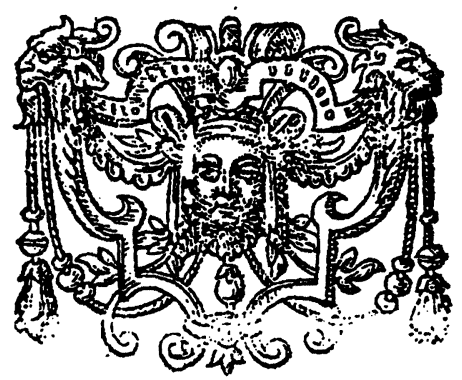

EN.AMBERES

En cafa de Hieronymo Verduffen. M. DC. $x$.

Con Primilcgio.

Figura 2. Portada de la edición original de las "Relaciones de Pedro Teixeira» 
Se ignora el tiempo que Teixeira permaneció en Venecia, su pista se pierde por Italia y Francia, y sólo vuelve a recuperarse en Amberes -ciudad que contaba con una numerosa colonia de españoles y portugueses-, donde se establece hacia 1608. Allí daría los últimos retoques a sus $R e$ laciones, que finalmente se editaron en 1610, y en esa ciudad moriría según afirman algunos historiadores, con Barbosa Machado a la cabeza, aunque Kayserling cita a varios autores que afirman que falleció en Verona ${ }^{12}$.

Del carácter, de la personalidad de Pedro Teixeira tampoco sabemos mucho más de cuanto se puede deducir de la lectura de su crónica viajera. En ella se nos presenta como un hombre cauto, precavido, y buen administrador de los recursos económicos. También parece un hombre de moralidad intachable, religioso y provisto de un gran sentido común, que evidencia una enorme afición por la lectura, en particular de los libros de «humanas historias» -así lo afirma expresamente en la introducción al lector de sus Relaciones-, y por las ciencias naturales y la farmacología, lo que evidencia en su obra dedicando no pocos párrafos a describir las propiedades curativas de las plantas y las piedras que encuentra, así como las enfermedades de hombres y animales. Un rasgo destacable de Teixeira es su iberismo, su "conciencia de ser hispano» ${ }^{13}$, reflejada en que cuando habla de España o los españoles lo hace, a menudo, empleando los posesivos "nuestra» o "nuestros", exactamante igual a como los usa cuando se refiere a Portugal y los portugueses.

Teixeira, en fin, se nos aparece como un hombre de gran inteligencia y con buena disposición para el estudio y el aprendizaje de idiomas, de los que dominaba varios (portugués, castellano, persa, árabe y rudimentariamente otros dialectos orientales), aunque se nos muestre más como un hombre de acción que de estudio. Sinclair ${ }^{14}$ lo considera «uno de los primeros, o el primero, de los tratamundos (...), tan cuidadoso y crítico como podía esperarse en aquella época».

\section{Las relaciones de Pedro Teixeira y su viaje por Mesopotamia}

La obra de Pedro Teixeira está dividida en tres partes de perfiles muy definidos. La primera comprende la Relacion de los Reyes de Persia, una Breve Relacion de las Provincias mas nobles y que mas han durado en el sennorio de la Persia, y unas tablas de los Reyes que sennorearon la Persia hasta la entrada de los Arabes segun Mirkond. La segunda parte se titula Relacion de los Reyes de Harmuz; y la tercera Relacion del Cami- 
Pedro Teixeira y su viaje por Mesopotamia

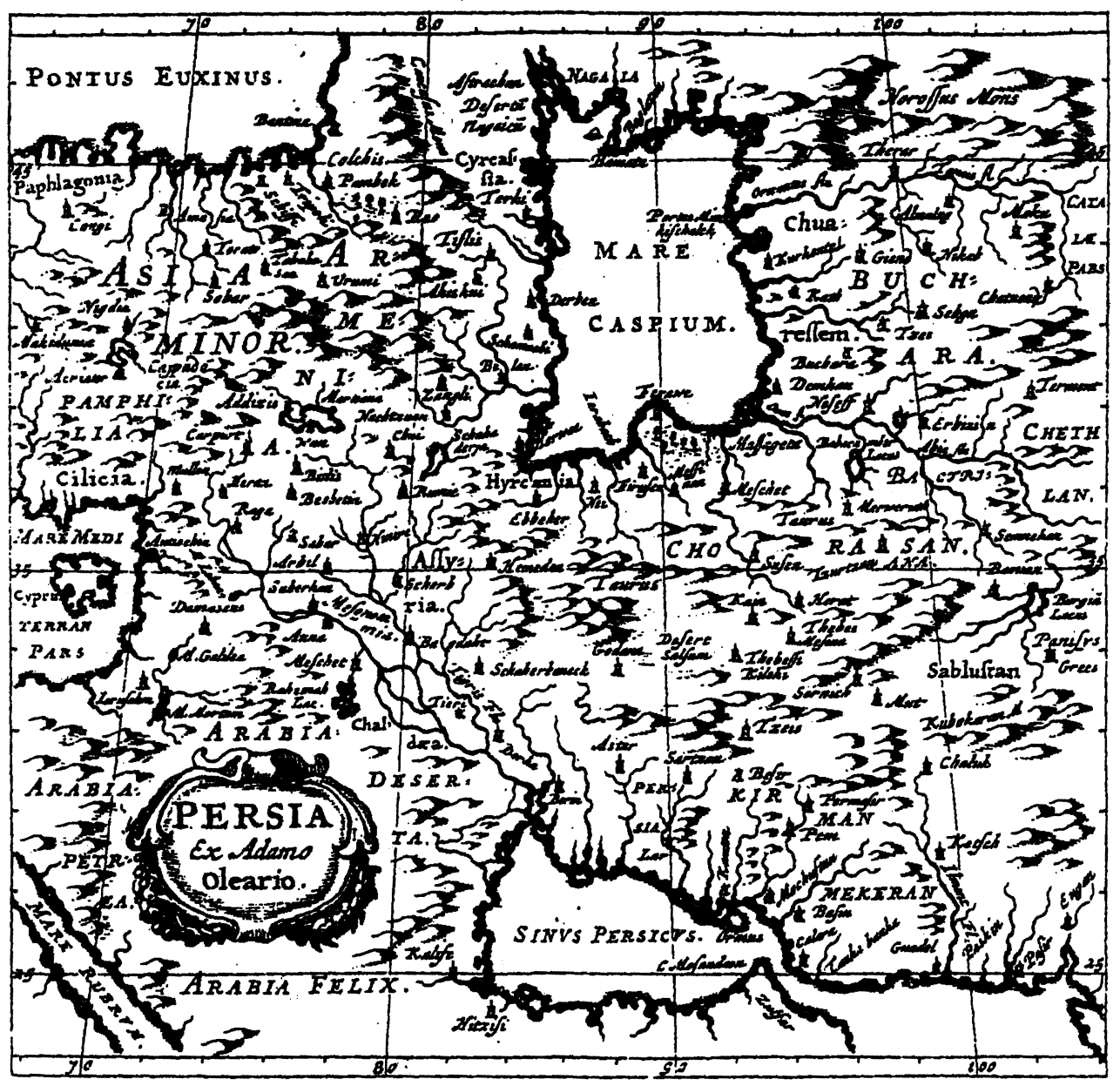

Figura 3. Mapa de Persia de Adamo Oleario, Amsterdam 1672 
no que hize dende la India hasta Italia. El conjunto va precedido de una introducción -Al lector- donde Teixeira expone su interés por la Historia y justifica la edición de su texto, explicando de paso que «primero comencé a escribir estas relaciones en mi lengua materna Portuguesa, y sólo el primer libro hasta la entrada de los Arabes en la Persia, y queriendo imprimir, por licencia que ya para ello tenía, mudé de parecer, obligado de la instancia y consejo de amigos, púselo en lengua Castellana añadiendo el segundo libro hasta nuestros días: juzgando que en esa lengua quedaba más comunicable» ${ }^{15}$.

El contenido de las Relaciones, como puede apreciarse por el esquema textual de la obra, es diverso y muy rico, especialmente en el campo histórico, sin desdeñar sus aportaciones en el ámbito de la etnografía, de las ciencias naturales y de la lingüística. Teixeira, en cualquier caso, era un simple aficionado a la historia, o poco más, pues no demuestra conocer a los historiadores clásicos grecolatinos, $\mathrm{y}$, por las referencias que ofrece en su texto, tampoco a los árabes ni a los persas salvo superficialmente. Aunque cita a algunos autores, para escribir su Relación de los Reyes de Persia sigue fielmente a Mirkhond ${ }^{16}$, como reconoce en el título general de la obra, sin añadir apenas nada a lo que el historiador persa dejara escrito.

La tercera parte de las Relaciones, sin duda la más interesante en cuanto al propósito que anima estas páginas, la Relacion del Camino que hize dende la India hasta Italia, ocupa una cuarta parte del volumen completo, y excepto el primer capítulo y los tres últimos de los quince que componen este texto, todos están dedicados a la narración de su viaje desde Ormuz hasta Alejandreta, a través de Mesopotamia, iniciado el 2 de septiembre de 1604 y concluido el 8 de abril de 1605 .

La primera etapa le condujo a Basora «entrando por los Ríos Tigris y Éufrates», que le causan una vivísima impresión, tanto por su extensión y caudal, como por la riqueza ganadera y abundancia de ánades que halla en sus riberas. Describe Basora como una ciudad de una «diez mil casas» protegida por una fortaleza cuadrada, más ancha que larga, cuyos muros de tierra estaban muy deteriorados. Destaca la fertilidad de sus campos y la red comercial establecida con Bagdad para la venta de su producción de dátiles, trigo, cebada, legumbres...

Desde Basora, enrolado en una caravana dirigida por un árabe de la localidad, a la que accede "por medio de un Mostafá Turco renegado de Judío, persona de quien los Portugueses y Venecianos que allí platican hacían mucha confianza», partió en compañía de Diego de Melo, un hidalgo criollo de la India, y del portugués Juan Pinto, hacia el segundo 
punto de destino, Mashad Ali (Mexat Aly escribe Teixeira), tras una durísima travesía por el desierto que se dilató durante dieciséis días. Teixeira realiza un breve apunte diario de esta etapa, y destaca que, como mucho, lograban avanzar veinte o treinta kilómetros diarios, sufriendo «la maleza del camino, ardor del sol, sed y hambre, y recelos de los ladrones árabes que muy de ordinario corren el desierto".

De Mashad Ali comienza explicando el significado de su nombre, "Mezquita de Alí»" ${ }^{17}$, y a continuación refiere brevemente el cisma abierto en el Islam entre los seguidores del yerno y primo de Mahoma y los «Sunis» (suníes), para narrar cómo una vez asesinado Alí, y según éste había ordenado, su cadáver fue puesto sobre un camello al que dejaron vagar libremente hasta que se detuvo en un determinado lugar del desierto, donde le dieron sepultura y erigieron un templo (que describe a grandes pinceladas) alrededor del cual se construyó la ciudad que se convirtió en un lugar santo del chiísmo. Asimismo nos informa de que Mashad Ali «está sujeta al Turco, a quien el Señor della, que es un Rey Árabe, reconoce con tributo». De la población afirma que «la mayor parte es blanca, pero toda de perversa naturaleza», para añadir que "no asienta en este pueblo Judío ni Cristiano alguno, porque les tienen a todos odio mortal: y no menos a todos los Moros que no son de su secta", aludiendo a la chií ${ }^{18}$.

La siguiente parada del lento viaje en caravana de Texeira se produjo en la actual Kerbala o Mashad Husein: «Mexat Oçem o Mam Oçem, que es Mezquita de Oçem», según escribe en las Relaciones, para añadir que «los naturales de Mexat Oçem son todos Rafazis, o, Xyahys, como los de Ali, y por consiguiente aborrecen cualquier otra secta y Ley, así de Moros, como de Cristianos y Judíos mortalmente, y de estos dos últimos ninguno vive en la tierra, y si acaso pasa por ella es muy mal visto». Luego Texeira describe la Mezquita donde está sepultado Husein, hijo de Alín ${ }^{19}$, otro de los lugares sagrados del chiísmo, y nos informa que tanto Mashad Ali como Mashad Husein están «sujetos a Mir Naçer, un Rey Árabe vasallo del Turco", al tiempo que recuerda al lector que por entonces Turquía y Persia estaban en guerra, y los comerciantes de Kerbala no tenían el menor reparo a la hora de vender armas y caballos a los turcos.

En Kerbala la caravana se divide, el grupo de Teixeira y su compatriota Diego de Melo debe retrasar su salida por falta de camellos y parte hacia Bagdad el día 2 de octubre de 1604. El 3 cruzan el Éufrates y el 4 entran en Bagdad, donde Texeira encuentra un cálido recibimiento por parte de un joven que se hacía llamar Diego Fernándes Alemán (aunque Teixeira apunta que realmente se llamaba Ioachim Ozemkrok 
y era natural de Hamburgo), a quien había conocido y ayudado en la India y ahora le devolvía los favores recibidos.

A Bagdad, Teixeira le dedica un capítulo espléndido que comienza con estas palabras: «Bagdad ciudad harto nombrada, está asentada sobre el río Tigris, llamado de los naturales Digilah, o Diguylah, como están Sevilla y Triana sobre el Guadalquivir». Tras esta poética comparación, el autor va recorriendo poco a poco todos los aspectos relevantes de la ciudad: el río, las mezquitas, los baños públicos, los edificios, la fortaleza del Baxá y su ejército, el clima, la agricultura, el mercado... De la población dice que «la mayor parte son Árabes políticos, el resto son Turcos, Curdes, y Agemis, o Persianos" y que "habrá de doscientas a trescientas casas de judíos», mientras que "de Cristianos Armenios había diez casas, y ochenta de Nestorianos». De los hombres destaca su cortesía, afabilidad y buen natural, así como que todos hablan tres idiomas: «Turco, Arábigo, y Agemy o Persiano». De las mujeres resalta su hermosura, con alusión especial a la magia de sus ojos, de efímera presencia, pues añade que "van todas cubiertas por las calles con unos paños como mantos, a que llaman chaudales, pero no de color negro, tapadas las caras con un cedazo o cendal negro o pavonazo, con que viendo ellas todo, no pueden ser vistas: aunque también no les pesa de serlo, y para ello se descubren aposta algunas veces». Para concluir el capítulo, cuenta la historia de la fundación de Bagdad, para aclarar que esta ciudad, erigida a orillas del Tigris, no es la Babilonia bíblica, asentada en la ribera del Éufrates, como mucha gente creía en Europa, fechando la fundación de Bagdad el año 145 de la Hégira (Hixara), 763 de la era cristiana.

La siguiente etapa del viaje de Texeira, que le conduciría a la población de Ana en el camino hacia Alepo, hubo de esperar a que ésta última ciudad se viera libre del cerco al que la sometía el ejército turco desde hacía ya tres meses. El 26 de noviembre de 1604, Diego Fernandes Alemán le notifica que el asedio ha concluido y el camino hacia Alepo está libre de obstáculos. El 12 de diciembre, una vez conseguidos los correspondientes camellos, cruzan el Tigris y en la otra parte de Mesopotamia emprenden viaje hacia el pueblo de Ana. El trayecto se narra mediante breves apuntes diarios que abarcan trece días.

De Ana (cuyo nombre, explica, quiere decir en árabe «pena» o «molestia») nos dice que está asentado en la ribera del río "Phorat o Éufrates», y que es una población antiquísima que ya se cita en el segundo Libro de los Reyes $^{20}$. De esta ciudad, Texeira realiza una descripción que sigue el mismo esquema dedicado a Bagdad, aunque en esta ocasión se detiene algo más en asuntos económicos (el comercio de dátiles con Damasco, Alepo y 


\section{Pedro Teixeira y su viaje por Mesopotamia}

Trípoli; los impuestos al tráfico comercial de las caravanas, etc.), y político-militares (el contingente de tropas que defiende la ciudad, la artillería, la corte del monarca local). En Ana, Teixeira se sorprende al hallar un gran número de hombres hilando lana con uso - mientras que las mujeres usaban la rueda-, y añade que, por más que no fuera extraño ver a los varones desempeñando tal actividad en Mesopotamia, «en ninguna otra parte me acuerdo de haber visto tantos hilanderos como en ésta».

Teixeira y su caravana de camellos (cafila), partieron de Ana el 13 de enero de 1605, y caminaron a un promedio de cinco o seis leguas diarias, a veces nueve, por el desierto de Sukana, hasta alcanzar el pueblo de igual nombre el 31 de enero. Durante la exposición de las agotadoras marchas, narrada como ya es norma en Teixeira jornada a jornada, se suceden las descripciones geográficas, algunas especialmente bellas como la que realiza de su paso por las montañas Rumamhen, que se alzan majestuosas en la inmensa soledad del desierto y cuyo nombre significa «las dos Granadas», "nombre cierto muy proprio y acomodado por su figura», apostilla Teixeira; pero también menudean las etnográficas, como la descripción de dos poblados (cabildas) de turcomanos dedicados a la ganadería, una de las cuales, nos detalla, se asentaba «en una sierra que los Árabes llaman Gibel el Bexar (que es) el monte o sierra de Bexar nombre de una cabilda dellos, y quizá que en memoria de aquella, lo dieron los Árabes en nuestra España a Bexar de que el Duque se intitula».

En Sukana, cuyo nombre proviene «del Arábigo Sukan que quiere decir caliente», nos explica Teixeira, "por una fuente de agua azucarada, caliente y hedionda... que da nombre a la tierra", la caravana se detuvo cinco días.

El 5 de febrero salieron de Sukana en dirección a Alepo, adonde llegaron una semana después, tras sufrir el día 9 el asalto de una partida de trescientos ladrones que lograron llevarse dos centenares de camellos cargados de dátiles, y obligaron a los viajeros a defenderse, «quien al arcabuz y quien a los arcos», para conservar la vida.

En Alepo permanecerá Teixeira casi dos meses, hasta el 5 de abril de 1605 , tiempo más que suficiente para conocer la ciudad hasta sus últimos detalles. La descripción urbana de Alepo, junto a la que dedica a Bagdad, constituyen quizá las mejores páginas de las Relaciones. De Alepo menciona sus cuarenta y cinco barrios (veinte en el interior y veinticinco fuera de los muros que rodean la ciudad) y sus «veintiséis mil casas de buena fábrica, en general de piedra bien labrada, pero en particular muchas de tanta grandeza, costa, curiosidad cuanto se puede desear: y no sólo de los Turcos y Moros son de aquesta suerte, pero aun de las de los Judíos, 
y Cristianos Griegos y Armenios son muchas de tanto precio que son capaces de hacer en ellas Príncipes». A continuación se asombra de sus trescientas bellísimas mezquitas y de las losas de mármol que cubren las calles, y celebra la existencia del Hospital Real, así como de las numerosas boticas que encuentra en la ciudad.

La población de Alepo, nos informa Teixeira, estaba compuesta mayoritariamente por "Moros naturales y Turcos», y en consecuencia las lenguas oficiales de la ciudad eran el árabe y el turco, "aunque por causa del comercio hablan muchos el Italiano, Francés, Inglés, y algunos Español». Además, nos dice, en Alepo existían núcleos importantes de «diversos Cristianos: Armenios, Maronitas, Caldeos y Griegos», que se suman a la importante colonia judía «de los cuales habrá mil casas buenas en barrio separado, pero dentro de los muros, con una grande Sinagoga que afirman haber mil quinientos años que fue fundada".

La ciudad es un centro comercial de primera magnitud, donde Francia, Inglaterra, Venecia y Flandes mantienen su propio consulado para proteger sus respectivos intereses económicos, de los que Teixeira nos da cuenta por extenso, tanto los referidos a los principales productos manufacturados en la propia ciudad de Alepo (sedas, jabones, objetos de vidrio...), como aquellos que eran transportados en caravanas desde lugares remotos para ser embarcados luego hacia Europa (paños, brocados, algodón, canela, clavo...), usando la ciudad como mercado.

Por fin, el 5 de abril de 1605 la caravana de Teixeira sale para Alejandreta (la pequeña Alejandría), y alcanza su destino el día 8. Cuatro días después, sin apenas tiempo de conocer la ciudad, Teixeira se embarca en una nave veneciana que aportará en la ciudad del Adriático, después de un azaroso viaje con escalas en Salinas, Chipre y Zante, el 11 de julio de 1605 .

Tal es, en resumen, el itinerario seguido por Pedro Teixeira en su viaje por Mesopotamia. La descripción de las ciudades que visita, sus comentarios etnográficos e históricos, sus explicaciones etimológicas, las observaciones, en fin, de todo tipo reunidas en su Relación del Camino, convierten a libro y autor en unos clásicos indiscutibles en el ámbito de la literatura viajera por Oriente Próximo. El texto puede ser ahora consultado sin dificultad por cualquier lector curioso gracias a la gran labor realizada hace poco más de una década por el profesor Eduardo Barajas Sala, a quien, en el momento de poner punto final a estas notas, vuelvo a rendir mi tributo de admiración y respeto. 


\section{Pedro Teixeira y su viaje por Mesopotamia}

\section{Notas}

${ }^{1}$ La edición original se realizó en Amberes en 1610, en la casa de Hieronymo Verdussen. Su primera traducción, aunque fragmentaria, fue al latín, firmada por el belga Jean de Laet, en 1633. Al francés la vertió con enormes errores Ch. Cotolendi en 1681, con el título de Voyages de Pedro Teixeira ou l'Histoire des Rois de Perse. En inglés, por el contrario, las Relaciones conocen dos buenas ediciones, aunque ninguna contenga el texto completo del original de Amberes: la realizada por John Stevens en 1715 (The History of Persia (...) by Anthony Teixeira. London, J. Brown), y la de William F. Sinclair y Donald Ferguson en 1902 (The Travels of Pedro Teixeira. The Hakluyt Society. London), que fue reeditada en 1967 por Kraus Reprint en Nendeln (Lienchtenstein).

2 Introducción y edición de Eduardo BARAJAS. Colección «Biblioteca de Viajeros Hispánicos», Miraguano Ediciones/Ediciones Polifemo, Madrid 1994.

3 Eduardo Barajas, Las "Relaciones" de Pedro Teixeira (Amberes, 1610). I. Portuguesismos lexicos: Los Fitonimos. Guimaraes. Companhia editora do Minho. Fevreiro de 1989. Barcelos.

${ }^{4}$ La edición original de Peregrinaçao (Lisboa, 1614), dedicada a Felipe III, se imprimió 31 años después de la muerte del autor; la traducción al castellano fue realizada por Francisco HERRERA MALDONADO y se publicó en Madrid el año 1620, y se reproduce en la moderna edición anotada de Las Peregrinaciones de José Agustín Mahieu, Alfaguara, Madrid 1982.

5 Editado con ese título en la «Biblioteca de Viajeros Hispánicos», Miraguano Ediciones/Ediciones Polifemo, Madrid 1983. El título de la edición original portuguesa de 1624 es Novo Descobrimiento do Gram Cathayo, ou Reinos de Tibet pello Padre António de Andrade da Companhia de IESU, portuguez no anno de 1624, publicada en Lisboa por Matheus Pinheiro.

${ }^{6}$ Ver Charles David Ley (2000), Luis GraÇa (1963) y Alfredo PinHeiro Marques (1991) en Bibliografía.

7 Editada por Joaquín Veríssimo SERRAo (1973). Ver Bibliografía.

8 Códice CXV-1-5, de la Biblioteca Pública de Évora. Referencia de Eduardo BARAJAS, Relaciones, op. cit, p. XLIII.

9 En sus respectivas introducciones a las ediciones inglesa y española ya citadas en las notas 1 y 2.

10 Citado por Donald Ferguson y Eduardo Barajas. Referencia al texto de Meyer Kayserling (1858), y a su traducción al inglés por Israel Joseph Benjamin (1859), ver Bibliografía. El posible origen judío de Teixeira lo mantiene la Jewish Encyclopedia, que en su edición digital, citando a Kayserling, incluye su biografía y destaca sus Relaciones "como una fuente de información sobre los judíos de Alepo, Bagdad y otras ciudades, con anotaciones sobre los monumentos judíos".

11 Este viaje lo reflejó Teixeira en el capítulo I de la Relación del Camino que hice dende la India hasta Italia, incluida en sus Relaciones.

12 Diogo Barbosa Machado, Biblioteca Lusitana Occidental (4 Vol.), iii, 622. Lisboa, $\mathrm{Na}$ Oficina de Inacio Rodrigues 1747. Existe reedición moderna por Manuel Lopes de Almeida, Atlântida Editora, Coimbra 1965-1967. Meyer Kaiserling, ver Bibliografía, cita al cordobés Miguel De Barrios (1635-1701), Relación de los poetas y escritores españoles de la nación judaica amstelodana (Amsterdam, 1683); a Wolf, Bibl. Hebr, 922; y a Leopoldo Zunz, Gesammelte Schriften, i, 188, entre otros autores, que sostienen la tesis de Verona como ciudad en la que murió Teixeira. 
13 En palabras de Eduardo BARAJAS (Introducción a su edición de las Relaciones, op. cit., pág. XX).

14 Introduction a la edición inglesa de 1902, op. cit., pág. XCIX. Ver Bibliografía.

15 Pedro TeIXeIRa, Relaciones, op. cit. p. 4.

16 Mirkhond, Mir Kwand o MirJwand (Muhammad ibn Jawasah ibn Mahmud, 14431498), historiador persa cuya obra principal fue una gran recopilación de historia universal titulada Rawzat as-safa', que abarcaba desde la creación del mundo hasta la época del autor.

17 En realidad Mashad significa "tumba". Alí (? ca.599-Kufa 661) fue el cuarto califa ortodoxo del Islam, proclamado tras el asesinato de Utman en el 656, con la oposición de Aisa, la viuda del Profeta, y del omeya Muhawiya. Fue asesinado por un jariyita, dando así comienzo al califato Omeya.

18 El chiísmo se convierte en la religión oficial de Persia desde principios del s. XVI, por decisión del primer sha de la dinastía safawida Ismael I.

19 Husein, hijo de Alí y nieto del Profeta, tercer imam de los chiíes, decapitado en Kerbala que por ello es conocida como Mashad al Husein («Tumba de Husein»), situada en la mezquita de Abbas.

20 Aparece citada, en efecto, en capítulo XIX, versículo 13.

\section{Bibliografia}

BARAJAS SALA, Eduardo (1994): «Introducción» a las Relaciones de Pedro Teixeira del Origen, Descendencia y Sucesión de los Reyes de Persia, y de Harmuz, y de un Viaje hecho por el autor dende la India Oriental hasta Italia por tierra. Miraguano Ediciones/ Ediciones Polifemo, Madrid.

- (1989): 989): Las "Relaciones" de Pedro Teixeira (Amberes, 1610). I. Portuguesismos lexicos: Los Fitonimos. Companhia Editora do Minho, Barcelos.

Boxer, C.R (1991): The Portuguese Seaborne Empire 1415-1825. Carcanet (también Hutchinson, 1969), London.

Ferguson, Donald (1902): «Introducción" a The Travels of Pedro Teixeira. With his "Kings of Harmuz" and extracts from his "Kings of Persia", translated and annotated by William F. Sinclair. With further notes and introduction by Donald Ferguson. Printed by The Hakluyt Society, London.

GraçA, Luis (1963): A visao do Oriente na literatura Portuguesa de viagens: Os viajantes Portugueses e os itinerarios terrestres (1560-1670). INCM, Lisboa.

Kayserling, M (1858): Pedro Teixeira: Eine Reiseskizze als Einleitung zu J.J.Benjamin, Acht Jahre in Asien und Africa. Hanover. Con traducción al inglés como: BENJAMIN, ISRAEL JOSEPH (1859): Eight Years in Asia and Africa from 1846 to 1855: With a Map, Woodcuts, and Corresponding Notes from... Pedro Teixeira. With an introduction on Teixeira by M. Kayserling. Hannover Publisher.

LEY, Charles David (1947): Portuguese Voyages (1498-1663). J.M. Dent and Everyman's Lybrary London, 1965 (primera edición de 1947). Reeditada también por Phoenix Press, London, 2000.

Pearson, M.N. (1987): The Portuguese in India (History of India, I:1). Cambridge University Press.

Pinheiro MARques, Alfredo (1991): A historiografia dos decobrimentos e expansao portuguesa. Coimbra, Liviraria Minerva. 


\section{Pedro Teixeira y su viaje por Mesopotamia}

SERRAo, Joaquin Veríssimo (1973): A Historiografia Portuguesa (2. Vol). Ed. Verbo, Lisboa. SERRAO, Joaquin Veríssimo (1979): Historia de Portugal. Ed. Verbo, Lisboa.

Subrahmanyam, Sanjay (1993): The Portuguese Empire in Asia 1500-1700. Longman, London. 